\title{
BMJ Open Musculoskeletal pain and limitations in work ability in Swedish marines: a cross-sectional survey of prevalence and associated factors
}

\author{
Andreas Monnier, ${ }^{1,2}$ Helena Larsson, ${ }^{1,3}$ Mats Djupsjöbacka, ${ }^{4}$ Lars-Åke Brodin, ${ }^{5}$ \\ Björn O Äng ${ }^{1,6,7}$
}

To cite: Monnier A, Larsson H, Djupsjöbacka M, et al. Musculoskeletal pain and limitations in work ability in Swedish marines: a crosssectional survey of prevalence and associated factors. BMJ Open 2015;5: e007943. doi:10.1136/ bmjopen-2015-007943

- Prepublication history and additional material is available. To view please visit the journal (http://dx.doi.org/ 10.1136/bmjopen-2015007943)

Received 11 February 2015 Revised 1 September 2015 Accepted 15 September 2015

CrossMark

For numbered affiliations see end of article.

Correspondence to Andreas Monnier; andreas.monnier@ki.se

\section{ABSTRACT}

Objectives: To estimate the prevalence of self-rated musculoskeletal pain and pain limiting work ability in Swedish Armed Forces (SAF) marines, and to study factors potentially associated with pain limiting work ability for the most prevalent pain regions reported.

Design: Population-based, cross-sectional survey. Participants: There were 272 SAF marines from the main marine battalion in Sweden included in the study. Outcomes: Self-assessed musculoskeletal pain and pain limiting the marines' work ability within a 6month period, as obtained from structured questionnaires. The association of individual, health and work-related factors with musculoskeletal pain limiting work ability was systematically regressed with multiple logistic models, estimating $\mathrm{OR}$ and $95 \% \mathrm{Cl}$.

Results: Musculoskeletal pain and pain limiting work ability were most common in the back, at $46 \%$ and $20 \%$, and lower extremities at $51 \%$ and $29 \%$, respectively. Physical training $\leq 1$ day/week (OR 5.3 , $95 \% \mathrm{Cl} 1.7$ to 16.8 ); body height $\leq 1.80 \mathrm{~m}$ (OR 5.0 , $95 \% \mathrm{Cl} 1.6$ to 15.1 ) and $\geq 1.86 \mathrm{~m} \mathrm{(OR} \mathrm{4.4,95 \%} \mathrm{Cl} 1.4$ to 14.1); computer work $1 / 4$ of the working day (OR $3.2,95 \% \mathrm{Cl} 1.0$ to 10.0 ) and $\geq 1 / 2(\mathrm{OR} 3.3,95 \% \mathrm{Cl}$ 1.1 to 10.1 ) of the working day were independently associated with back pain limiting work ability. None of the studied variables emerged significantly associated with such pain for the lower extremities.

Conclusions: Our findings show that musculoskeletal pain and resultant limitations in work ability are common in SAF marines. Low frequency of physical training emerged independently associated with back pain limiting work ability. This suggests that marines performing physical training 1 day per week or less are suitable candidates for further medical evaluation and secondary preventive actions. While also associated, body height and computer work need further exploration as underlying mechanisms for back pain limiting work ability. Further prospective studies are necessary to clarify the direction of causality.

\section{BACKGROUND}

The Swedish Armed Forces (SAF) marine's primary tasks include the ability to seize and

\section{Strengths and limitations of this study}

- This study fills an important gap concerning evidence with regard to musculoskeletal pain that limits work ability in marines and in addition, the identified associated factors pave the way for further prospective studies.

- The outcomes are based on international consensus definitions of pain and its impact on work ability.

- Causal inferences are limited due to the crosssectional design of the study.

- Retrospective self-assessment of pain and work exposures might suffer from recall bias and lack of accuracy.

control coastal areas, with high requirements for sea and land mobility of its units. To meet such operational flexibility, marines' training and daily work-tasks are often physically demanding, and in general perceived to be closely related to a high occurrence of musculoskeletal pain. Although scientific evidence is lacking for SAF marines, high musculoskeletal pain prevalence has been reported internationally for similar military units, ${ }^{1}{ }^{2}$ which was also related to reduction in training-ability ${ }^{2}$ and medical downgrading of personnel to non-deployment status. ${ }^{1}$ Presenteeism is common for this occupational group, and limitations in work-ability in one marine increases the workload of the rest of the unit, for example, carrying more load per person and working longer or extra shifts, ${ }^{3}{ }^{4}$ thereby also increasing their risk exposure. As such, musculoskeletal pain episodes are to be considered a threat to the operational readiness of SAF marines and therefore, its prevention should be of great importance.

For marines internationally, just like the general military population and civilian 
society, the lower back is the most frequently reported area of musculoskeletal pain, with a global 1 year prevalence of approximately $38 \% .^{5}$ In contrast to the general civilian population where back pain prevalence is closely followed by the prevalence of neck pain, ${ }^{6}$ lower extremities seem to be the second most affected region within elite and expeditionary units such as marines. ${ }^{7} 8$ Previous studies in other military populations, mainly those including recruits or soldiers under deployment, have identified prior injuries as the primary risk factor for development of new pain episodes or injuries. ${ }^{9-11}$ Other risk factors include being of female gender, ${ }^{12} 13$ older age, ${ }^{4} \quad 9 \quad 12 \quad 14$ high or low body mass index (BMI), ${ }^{11}{ }^{15}$ possessing low levels of physical capacity, ${ }_{17}^{16}$ and the intensity of work and physical training. ${ }^{9} 16{ }^{1} 17$ However, to our knowledge, no studies have examined if such risk factors are associated with musculoskeletal pain that limits work ability in non-deployed, active duty marines. Also, potential risk factors identified in civilian occupations may not be valid for marines due to homogeneity in age and gender, as well as selection and physical preparations for specific work tasks to an extent not commonly seen in civilian occupations. Together with a lack of knowledge regarding the occurrence and consequences of musculoskeletal pain, this limits evidencebased prevention for this group of military personnel. In Sweden, as in several other European countries with professional armed forces, such knowledge is not only required by the military community but also by the civilian society since a substantial percentage of the marines in the SAF will either work part-time in the forces while simultaneously pursuing civilian careers, or work fulltime for a maximum of 8 years before transitioning to a civilian occupation. In this first study, therefore, we estimated the prevalence of musculoskeletal pain and pain limiting work ability in SAF marines. We also investigated factors potentially associated with musculoskeletal pain limiting work ability for the most prevalent regions reported.

\section{METHODS}

\section{Study design}

This study used a cross-sectional design for a population of SAF marines. A single set of structured self-assessment questionnaires was administered to the marines over the course of a year, a process initiated in the autumn of 2010. Confidentiality, together with the fact that participation was voluntary, was stressed during the recruitment and enrolment process. Written and oral information was given prior to participation and signed informed consent was obtained from all participants enrolled in the study.

\section{Participants}

All eligible marines at the main marine battalion in Sweden, the 2nd Amphibious Battalion, in service at the 1st marine regiment Berga, Sweden, were (following an information gathering at each company) asked to participate in the study. To be eligible for inclusion, participants had to be on active service as a full-time marine for the past 6 months, that is, exclusion of participants temporarily posted or under training at the battalion and participants who had not worked as a marine in the past 6 months due to leave, studies, etc. Additionally, marines belonging to the battalion but on service elsewhere $(n=66)$ were not assessed for participation in the study. Of a total of 331 marines assessed for eligibility, 272 were included in the study (approximately $69 \%$ of the battalion $(n=397)$ at that time point). Forty-three did not fulfil the inclusion criteria (temporarily posted/under training at the battalion, $\mathrm{n}=8$; worked as a marine $<6$ months, $\mathrm{n}=28$; unable to work the past 6 months due to study/ parental-leave, $n=7$ ), nine declined participation in the study and seven did not respond when asked to participate. The mean (SD) age, body weight, body height and BMI of the included participants were as follow: 25.3 (6.7) years, $83(10.7) \mathrm{kg}, 1.82(0.07) \mathrm{m}$ and 25.1(2.7) BMI, respectively. The majority of the participants were men, $97 \%$, serving as marine infantry (43\%). Fifteen per cent of the participants served as combat craft-crews, $14 \%$ as rangers, and $18 \%$ were in logistical, command or intelligence functions.

\section{Questionnaires}

The occurrence of musculoskeletal pain in the past 6 months was self-assessed for nine anatomical areas, ${ }^{18}$ illustrated by a questionnaire-mannequin (figure 1) as 'No pain', 'Pain a couple a days per month or less' and 'Pain a couple of days per week or more'. If participants rated any of the pain alternatives, they were requested to assess to what extent it had limited their work ability or prevented performance of normal daily tasks. This was rated as 'not limited', 'limited to some extent' or 'limited to a large extent'.

The questionnaires also included demographic (age, body weight, body height, gender and smoking habits) and health-related (mental and physical) information, health-related quality of life (HRQL) and information regarding work exposures. Training frequency was rated as average number of days during a week with physical training for $>20$ min. ${ }^{19}$ Average hours per week for muscular strength and aerobic fitness training, respectively, were collected using an item previously used in several studies of Swedish military populations. ${ }^{20}$ HRQL was measured with Short Form-36 Health Survey (SF-36). The SF-36 is a generic, self-rated measure of health. The 36 items sum up to eight scale scores, ranging from 0 to 100 (100 indicates the best possible health outcome). These scores can be further aggregated to create two norm-based index summaries, the mental component summary and the physical component summary. The mean norm-based score for each component in the general Swedish population is 50 . While there is a newer version of the survey (SF-36 2.0), the version of SF-36 used in this study (IQOLA SF-36 Standard Swedish V.1.0, distributed from the HRQL-group in 2010) is used extensively and has been tested for validity 


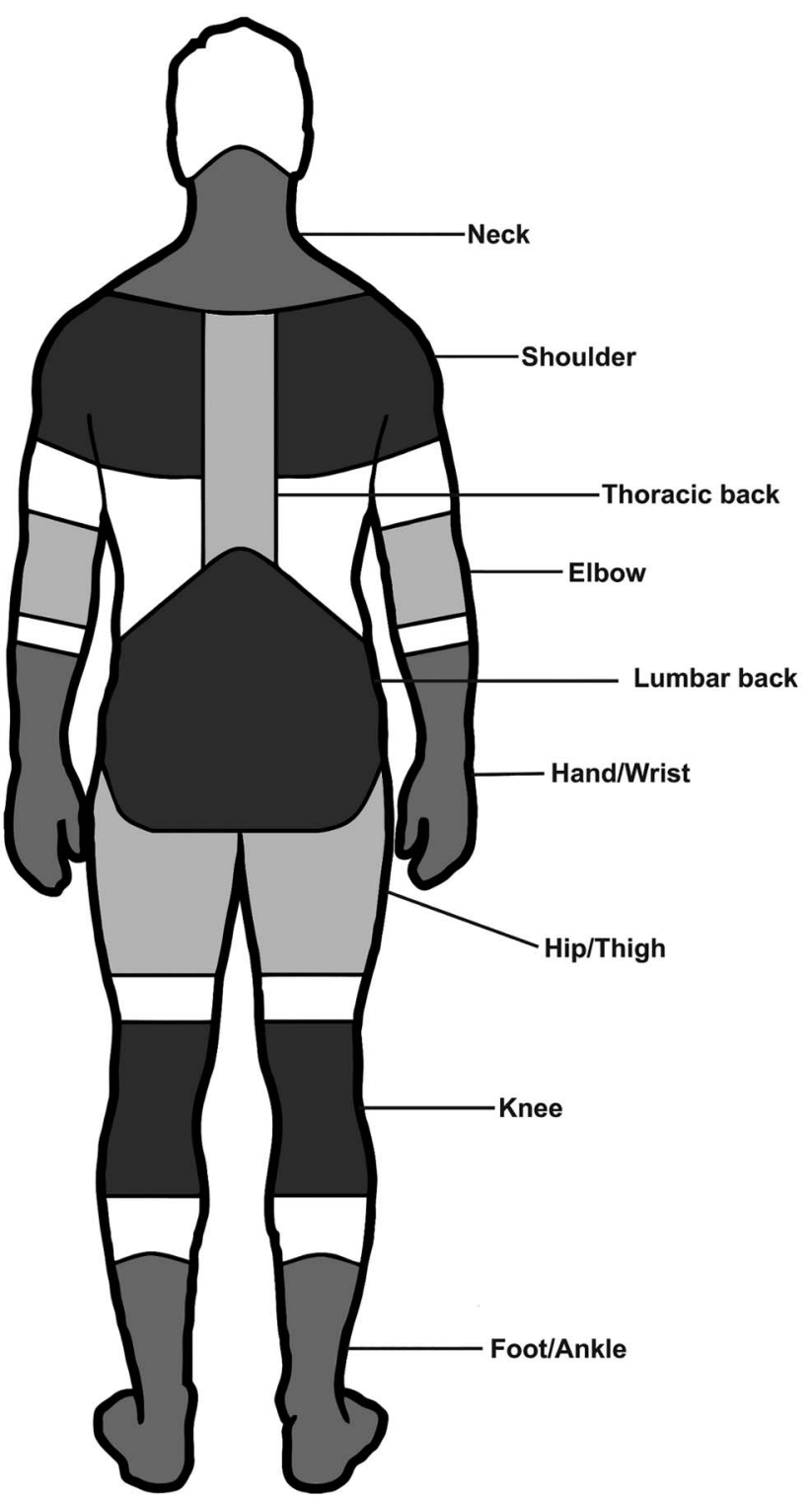

Figure 1 Questionnaire-mannequin illustrating defined anatomical areas for self-report of occurrence of musculoskeletal pain.

as well as reliability in the general Swedish population. ${ }^{21}$ The questionnaires further included items regarding time in current military occupation specialty, total time working with similar tasks, as well as average time per week in an operating combat craft (ie, high-speed combat boat). Three items covering exposure to vibrating floor and/or seat, sitting and computer work were self-rated as proportions of an average working day. Also, days per week with work tasks including lifting (5-15 kg and $>15 \mathrm{~kg}$ ) were rated. All selected task and exposure variables were previously used $^{19}$ and found to be reliable ${ }^{22}$ for Swedish public health cohorts.

Independent variables-individual, health and work-related factors

Seventeen factors ( 4 individual, 4 health-related and 9 work-related), listed in online supplementary table S1, were considered to possibly be associated with limitations in work ability due to musculoskeletal pain. These factors were selected based on existing evidence about musculoskeletal pain in civilian ${ }^{52-25}$ and military populations, ${ }^{13-16}$ and empirical knowledge from SAF marines' occupational health service. All continuous variables, with the exception of $\mathrm{BMI}$, were converted to tertiles to avoid violation of 'the assumption of linearity' and further adjusted, if necessary, to allow for meaningful interpretation. For example, the upper category of time in present military occupational specialty was adjusted from 20 to 24 months, yielding categories of $\leq 12$ months, 13-24 months and $\geq 25$ months. BMI was calculated as weight $(\mathrm{kg}) /$ height $(\mathrm{m})^{2}$ and was used as a continuous variable as the normal categorisation of overweight has been suggested to be lacking in accuracy for trained subjects. ${ }^{26}$ Further, the ranges for categories based on tertiles were deemed too narrow for meaningful clinical interpretation. Categorical data for rated work exposures were converted to three categories with the lowest category regarded as reference category. From reported occupational specialty, participants were classified into six different categories of military occupational functions based on the most frequent common work tasks with the most prevalent function (marine assault infantry) used as reference occupational function. See online supplementary table S2 for details about common work tasks, main characteristics and military occupational specialties for the different occupational functions. Based on our clinical experience of this type of soldier, a u-shaped relationship with musculoskeletal pain was hypothesised for physical training and body height, that is, too little and too much training and 'too tall or too short' may both be negative for musculoskeletal health. Consequently, the middle category was used as the reference category for these variables.

\section{Musculoskeletal pain and dependent variables}

Musculoskeletal pain was defined as any self-reported episode of pain within the past 6 months. This definition was selected to avoid uncertainties concerning the underestimation of pain occurrence commonly seen in similar types of military personnel, ${ }^{27}$ and has previously been used for this population. ${ }^{28}$ Musculoskeletal pain limiting work ability was defined as musculoskeletal pain that had limited work ability or restricted performance of normal daily tasks for that specified anatomical area. The nine anatomical areas were merged into four separate overall regions; (1) back (lumbar/lower and thoracic/upper back), (2) neck/shoulder, (3) lower extremity (hip/thigh, knee and ankle/foot) and (4) upper extremity (elbow and wrist/hand).

Participants reporting pain limiting work ability as compared to participants who rated no pain were used to operationalise our binomial-dependent variables when regressing independent variables as potentially associated for the most prevalent regions. This allowed us to proceed with regression analyses on polarised 
groups while omitting the diluting group reporting pain that was not limiting work ability in these analyses.

\section{Confounding variables}

Of three possible confounders a priori considered relevant (gender, smoking and non-musculoskeletal comorbidity such as cancer, tumours, respiratory or cardiovascular disease) only non-musculoskeletal comorbidity was found to have a confounding effect $(>10 \%$ change of OR in adjusted to crude model) and therefore, was included in all fitted models. In addition, the final multiple model was also adjusted for age and BMI, as these factors were identified as confounders during the purposeful selection process. ${ }^{29}$

\section{Data management and statistics}

\section{Missing data}

Overall, $1 \%$ of data were missing in the complete data set and handled as pair-wise deletion, that is, cases with missing data were excluded from that specific analysis, but included in the analysis for which they encompassed all the necessary data.

\section{Descriptive statistics-HRQL and musculoskeletal pain}

The eight SF-36 scale scores and two norm-based index scores were calculated and summarised using a standardised scoring algorithm ${ }^{21}$ and are reported with the mean (SD) and 95\% CI. Six-month prevalence of pain and pain limiting work ability is reported as a percentage with $95 \%$ CI.

\section{Regression analysis}

To avoid problems associated with colinearity, one of the independent variables in a pair identified to be at high risk of colinearity (Spearman's $r>0.6$ ) was excluded from the analysis (the variable with the most plausible association in the model was retained).Variables for the final multiple regression models were selected through a purposeful selection process, as described by Hosmer et al. ${ }^{29}$ First, independent variables were analysed with univariate logistic regressions adjusted for the predefined confounder, that is, non-musculoskeletal comorbidity. Independent variables associated with the dependent variable at $\mathrm{p}<0.20$ were then included in a multiple logistic regression model. Thereafter, following an iterative process of deleting non-significant $(p>0.05)$, nonconfounding, or non-mediating variables, the model was refitted and verified..$^{29}$ To avoid risk of excluding important independent variables, deletion was conducted one variable at a time, retaining only those variables in the model that remained significantly associated or that have a confounding effect, as previously defined. Interaction among the variables in the main effect model was checked and included in the final model if significant at a level of $\mathrm{p}<0.05$. Hence, the final model contained only significant $(\mathrm{p}<0.05)$ independent variables and identified confounders, interactions and/or mediators. Results of the associated variables are reported as OR and 95\% CI. The predicted models were found to fit if the Hosmer and Lemeshow ${ }^{29}$ test for goodness of fit were non-significant, $\mathrm{p}>0.05$, and to have acceptable discrimination if the area under the receiver operating characteristic curve (AUC) was $>0.7 .^{29}$

\section{RESULTS}

Table 1 provides demographic and background data as well as self-rated general health and HRQL for the 272 marines who completed the questionnaires $(94 \%$ response rate). Good or excellent current health status was reported by $79 \%$ of respondents, with a mean (SD) SF-36 general health score of 83.7 (12.3) and mental

Table 1 Demographic data, self-rated general health and health-related quality of life for the prevalence sample* with corresponding $95 \% \mathrm{Cl}$

\begin{tabular}{|c|c|c|}
\hline & Mean (SD) & $95 \% \mathrm{Cl}$ \\
\hline Age (years) & $25.3(6.7)$ & 24.5 to 26.1 \\
\hline Body weight (kg) & $83.4(10.7)$ & 82.1 to 84.6 \\
\hline Body height (m) & $1.82(0.1)$ & 181.2 to 182.9 \\
\hline \multirow[t]{2}{*}{ Body mass index (BMI) } & $25.1(2.7)$ & 24.8 to 25.4 \\
\hline & Per cent (n) & $95 \% \mathrm{Cl}$ \\
\hline Gender, men & $97(265)$ & 94.8 to 98.8 \\
\hline \multicolumn{3}{|l|}{ Smoking } \\
\hline No & $89(242)$ & 84.7 to 92.1 \\
\hline Occasionally & $11(30)$ & 7.8 to 15.3 \\
\hline Yes & $0(0)$ & 0.0 to 1.4 \\
\hline \multicolumn{3}{|l|}{ Snus (smokeless tobacco) } \\
\hline No & $63(170)$ & 56.6 to 68.0 \\
\hline Yes & $37(100)$ & 31.3 to 42.6 \\
\hline $\begin{array}{l}\text { Non-musculoskeletal } \\
\text { comorbidity }\end{array}$ & $6.7(18)$ & 4.3 to 10.3 \\
\hline \multicolumn{3}{|l|}{ General health } \\
\hline Good & $94.4(251)$ & 90.9 to 96.6 \\
\hline \multirow[t]{2}{*}{ Less than good } & $5.6(15)$ & 3.5 to 9.1 \\
\hline & Mean (SD) & $95 \% \mathrm{Cl}$ \\
\hline \multicolumn{3}{|c|}{ Health-related quality of life } \\
\hline Physical functioning $†$ & $98.0(4.1)$ & 97.5 to 98.5 \\
\hline $\begin{array}{l}\text { Role limitations, } \\
\text { physical† }\end{array}$ & $93.0(20.3)$ & 90.6 to 95.5 \\
\hline Bodily paint & $83.1(17.8)$ & 80.8 to 85.2 \\
\hline $\begin{array}{l}\text { General health } \\
\text { perception } †\end{array}$ & $83.7(12.3)$ & 82.2 to 85.2 \\
\hline Vitality† & $73.2(13.0)$ & 71.6 to 74.7 \\
\hline Social functioningt & 95.1 (10.2) & 93.9 to 96.4 \\
\hline $\begin{array}{l}\text { Role limitations, } \\
\text { emotional }^{\dagger}\end{array}$ & $95.7(16.0)$ & 94.2 to 97.9 \\
\hline Mental health $†$ & $85.1(11.1)$ & 83.7 to 86.5 \\
\hline $\begin{array}{l}\text { Physical component } \\
\text { summary } \ddagger\end{array}$ & $53.8(4.9)$ & 53.2 to 54.4 \\
\hline $\begin{array}{l}\text { Mental component } \\
\text { summary } \ddagger\end{array}$ & $51.9(6.0)$ & 51.1 to 52.6 \\
\hline
\end{tabular}


health score of 85.1 (11.1) out of 100. The mean (SD) of the norm-based index score (with the general Swedish population mean of 50) for the physical component summary was 53.8 (4.9) and 51.9 (6.0) for the mental component summary.

Table 2 shows the prevalence of musculoskeletal pain and pain limiting work ability. Within the previous 6-month period, $78 \%$ had experienced musculoskeletal pain somewhere in the body and $50 \%$ of the respondents had experienced limitations in work ability due to musculoskeletal pain. The lower extremities and the region of lumbar and thoracic back were the most prevalent regions of reported pain, as well as for pain limiting work ability. These regions were, therefore, further defined as the dependent variables for the regression analysis. Pain in two or more body regions that limited work ability was reported by $16 \%$. For the specific anatomical areas, the 6 months prevalence of musculoskeletal pain was highest for the lumbar back, at 36\% (95\% CI $30.6 \%$ to $41.9 \%$ ) and the knee $35 \%$ (95\% CI $29.6 \%$ to $41 \%$ ). These were also the specific anatomical areas with the highest occurrence of pain limiting work ability at $15 \%(95 \%$ CI $11 \%$ to $19.4 \%)$ and $18 \%(95 \%$ CI $13.8 \%$ to $22.9 \%$ ) for the lumbar back and knee, respectively.

After the exclusion of marines who rated pain in the back or lower extremities that did not limit their work ability, 203 and 211 marines, respectively, were included in the regression analyses. High risk of colinearity $(r>0.6)$ was identified for body weight (with BMI and height, retained in the analysis), sitting work (with computer work, retained in the analysis), lifting $5-15 \mathrm{~kg}$ (with lifting $>15 \mathrm{~kg}$, retained in the analysis), total time with similar work tasks (with age, retained in the analysis), and time in current military occupational specialty (with age, retained in the analysis) and were, therefore, not included in the regression analysis.

Tables 3 and 4 show results of the initial univariate logistic regression analyses for back and lower extremity pain limiting work ability, specified for individual and rated health (table 3) and work-related variables (table 4). Age, body height, BMI, physical training frequency, work function, proportion of working day spent on computer work and lifting $(>15 \mathrm{~kg})$ emerged as associated $(\mathrm{p} \leq 0.20)$ with back pain limiting work ability. For limited work ability due to lower extremity pain, muscular strength training and mental component summary scores were associated at $\mathrm{p} \leq 0.20$.

Table 5 shows the results of the initial and final adjusted multiple logistic regression models for back pain limiting work ability. One individual, one health and one work-related variable showed significant association $(p<0.05)$ with back pain limiting work ability after the purposeful selection process: body height $\leq 1.80$ (OR $4.97,95 \%$ CI 1.64 to 15.08 ) and $\geq 1.86$ (OR 4.40 , $95 \%$ CI 1.38 to 14.05$)$; physical training one day/week or less (OR 5.29, 95\% CI 1.66 to 16.84); computer work on average $1 / 4$ of the working day (OR $3.22,95 \%$ CI 1.04 to 10.03 ) and $\geq 1 / 2$ of the working day (OR 3.34, 95\% CI 1.11 to 10.10). Diagnostic tests of the final model, adjusted for age (confounding with all variables), BMI (confounding with physical training and computer

Table 2 Six-month prevalence of musculoskeletal pain and pain limiting work ability in marines

\begin{tabular}{|c|c|c|c|c|c|}
\hline & \multirow[b]{2}{*}{$\mathbf{n}$} & \multicolumn{2}{|l|}{ Musculoskeletal pain } & \multicolumn{2}{|l|}{$\begin{array}{l}\text { Musculoskeletal pain } \\
\text { limiting work ability }\end{array}$} \\
\hline & & Percentage of cases (n) & $95 \% \mathrm{Cl}$ & Percentage of cases (n) & $95 \% \mathrm{Cl}$ \\
\hline \multicolumn{6}{|l|}{ Anatomical area } \\
\hline Neck & 272 & $19.5(53)$ & 15.2 to 24.6 & $5.5(15)$ & 3.4 to 8.9 \\
\hline Thoracic & 272 & $19.9(54)$ & 15.6 to 25.0 & $7.4(20)$ & 4.8 to 11.1 \\
\hline Lumbar & 272 & $36.0(98)$ & 30.6 to 41.9 & $14.7(40)$ & 11.0 to 19.4 \\
\hline Shoulder & 271 & $22.1(60)$ & 17.6 to 27.5 & $10.7(29)$ & 7.6 to 15.0 \\
\hline Elbow & 271 & $5.9(16)$ & 3.7 to 9.8 & $2.2(6)$ & 1.0 to 4.8 \\
\hline Hand & 265 & $9.1(24)$ & 6.2 to 13.1 & $5.3(14)$ & 3.2 to 8.7 \\
\hline Hip & 271 & $5.2(14)$ & 3.1 to 8.9 & $2.2(6)$ & 1.0 to 4.8 \\
\hline Knee & 268 & $35.1(94)$ & 29.6 to 41.0 & $17.9(48)$ & 13.8 to 22.9 \\
\hline Foot & 270 & $21.1(57)$ & 16.7 to 26.4 & $13.3(36)$ & 9.8 to 17.9 \\
\hline \multicolumn{6}{|l|}{ Merged region } \\
\hline Any region & 270 & $78.2(211)$ & 72.8 to 82.7 & $49.6(134)$ & 43.7 to 55.6 \\
\hline Back $^{*}$ & 272 & 45.6 (124) & 39.8 to 51.5 & $20.2(55)$ & 15.9 to 25.4 \\
\hline Lower extremity $†$ & 269 & $50.6(136)$ & 44.6 to 56.5 & $29.0(78)$ & 23.9 to 34.7 \\
\hline Neck/shoulder & 271 & $33.2(90)$ & 27.9 to 39.0 & $14.8(40)$ & 11.0 to 19.5 \\
\hline Upper extremity & 265 & $15.1(40)$ & 11.3 to 19.9 & $7.6(20)$ & 4.9 to 11.4 \\
\hline Multiple-regions§ & 268 & $45.6(124)$ & 40.4 to 52.3 & $16.4(44)$ & 12.5 to 21.3 \\
\hline \multicolumn{6}{|c|}{$\begin{array}{l}\text { The 6-months prevalence of pain and pain limiting work ability is reported as percentage of total prevalence sample with corresponding } 95 \% \text { Cl. } \\
\text { *Back: lumbar and thoracic. } \\
\text { †Lower extremity: hip, knee and foot. } \\
\text { fUpper extremity: elbow and hand. } \\
\text { §Multiple-regions: pain in two or more merged regions. }\end{array}$} \\
\hline
\end{tabular}


Table 3 Univariate regression analyses: adjusted OR for back and lower extremity pain limiting work ability, with individual and rated health factors

\begin{tabular}{|c|c|c|c|c|c|c|c|c|c|c|}
\hline & \multicolumn{5}{|c|}{ Back } & \multicolumn{5}{|c|}{ Lower extremity } \\
\hline & $\mathrm{n}$ & Cases (\%) & OR $^{*}$ & $95 \% \mathrm{Cl}$ & p Value & $\mathrm{n}$ & Cases n (\%) & OR $^{\star}$ & $95 \% \mathrm{Cl}$ & p Value \\
\hline \multicolumn{11}{|l|}{ Individual factors } \\
\hline \multicolumn{11}{|l|}{ Age (years) } \\
\hline$\leq 21$ & 84 & $13(15)$ & 1.00 & & & 91 & $33(36)$ & 1.00 & & \\
\hline $22-26$ & 57 & $10(18)$ & 1.15 & 0.47 to 2.84 & 0.763 & 58 & $18(31)$ & 0.80 & 0.39 to 1.61 & 0.525 \\
\hline$\geq 27$ & 60 & $30(50)$ & 5.60 & 2.55 to 12.26 & 0.000 & 61 & $27(44)$ & 1.37 & 0.70 to 2.67 & 0.361 \\
\hline BMI (continuous) & 200 & $52(26)$ & 1.14 & 1.01 to 1.28 & 0.035 & 209 & $78(37)$ & 0.98 & 0.87 to 1.09 & 0.655 \\
\hline \multicolumn{11}{|l|}{ Body height (m) } \\
\hline$\leq 1.80$ & 82 & $25(30)$ & 2.77 & 1.10 to 6.99 & 0.031 & 86 & $32(37)$ & 1.32 & 0.63 to 2.75 & 0.461 \\
\hline $1.81-1.85$ & 51 & 7 (14) & 1.00 & & & 52 & $16(31)$ & 1.00 & & \\
\hline$\geq 1.86$ & 68 & $21(31)$ & 2.83 & 1.09 to 7.34 & 0.033 & 72 & $30(42)$ & 1.59 & 0.75 to 3.38 & 0.228 \\
\hline \multicolumn{11}{|l|}{ Rated health factors } \\
\hline \multicolumn{11}{|c|}{ Physical training (days/week) } \\
\hline$\leq 1$ & 24 & $13(54)$ & 4.30 & 1.69 to 10.92 & 0.002 & 27 & $9(33)$ & 0.81 & 0.33 to 1.98 & 0.641 \\
\hline $2-4$ & 102 & 22 (22) & 1.00 & & & 103 & 39 (38) & 1.00 & & \\
\hline$\geq 5$ & 74 & $17(23)$ & 1.08 & 0.53 to 2.22 & 0.826 & 79 & $29(37)$ & 0.97 & 0.53 to 1.79 & 0.933 \\
\hline \multicolumn{11}{|c|}{ Aerobic fitness training (h/week) } \\
\hline$<0.3$ & 60 & $19(32)$ & 1.25 & 0.58 to 2.66 & 0.571 & 67 & $24(36)$ & 0.95 & 0.48 to 1.88 & 0.891 \\
\hline $0.3-3.0$ & 73 & $20(27)$ & 1.00 & & & 80 & $30(38)$ & 1.00 & & \\
\hline$>3.0$ & 57 & $13(23)$ & 0.79 & 0.35 to 1.8 & 0.571 & 49 & 19 (39) & 1.09 & 0.52 to 2.26 & 0.828 \\
\hline \multicolumn{11}{|c|}{ Muscular strength training (h/week) } \\
\hline$<1.5$ & 61 & $20(33)$ & 1.58 & 0.74 to 3.39 & 0.242 & 67 & $20(30)$ & 0.51 & 0.25 to 1.02 & 0.056 \\
\hline $1.5-3.5$ & 72 & $17(24)$ & 1.00 & & & 76 & $34(45)$ & 1.00 & & \\
\hline$>3.5$ & 66 & $16(24)$ & 1.04 & 0.47 to 2.27 & 0.931 & 65 & 24 (37) & 0.70 & 0.36 to 1.39 & 0.311 \\
\hline \multicolumn{11}{|c|}{ Mental component summary } \\
\hline$\leq 51.40$ & 70 & 24 (34) & 1.42 & 0.97 to 2.99 & 0.360 & 65 & 24 (37) & 0.74 & 0.37 to 1.50 & 0.400 \\
\hline $51.41-54.74$ & 58 & 11 (19) & 0.63 & 0.27 to 1.50 & 0.300 & 71 & 22 (31) & 0.58 & 0.29 to 1.17 & 0.127 \\
\hline$>54.75$ & 63 & $17(27)$ & 1.00 & & & 67 & 29 (43) & 1.00 & & \\
\hline
\end{tabular}

work) and non-musculoskeletal comorbidity, indicated good fit (Hosmer-Lemeshow test, $\mathrm{p}=0.49$ ) and acceptable discrimination (AUC of 0.82). Table 6 shows only the initial multiple logistic regression model for lower extremity pain limiting work ability because no final model with variables independently associated with the dependent variable at $\mathrm{p}<0.05$ nor with good fit and acceptable discrimination could be identified.

\section{DISCUSSION}

This study estimated the prevalence of self-rated musculoskeletal pain and pain limiting work ability in SAF marines, and associated factors were identified for the most prevalent pain regions reported. Despite overall good self-rated general and mental health, musculoskeletal pain was fairly prevalent in this population, limiting work ability in at least $50 \%$ once during the past 6-month period. Low frequency of physical training, body height and occupational computer work were identified to be independently associated with limitation in work ability due to back pain, while no variable emerged as independently associated with lower extremity pain limiting work ability.
This is the first study of musculoskeletal pain prevalence in SAF marines and its effect on work ability, and identification of associated factors. Based on the high response rate $(94 \%)$ and by comparing demographic characteristics to previous results, ${ }^{2} 414{ }^{30}$ the present cohort was found to be an adequately representative military marine sample similar also to other military cohorts. Nevertheless, the external validity of this study extends only to SAF marines on active national duty. The cross-sectional design is an important limitation in the interpretation of the temporal sequence of exposure and outcome, although it seems unlikely that certain variables (eg, tall or short body height) would be a consequence of back pain. Also, data from self-assessments are often criticised with respect to precision, ${ }^{31} \mathrm{com}-$ monly resulting in increased risk of bias due to overestimation or underestimation of exposure levels. Still, the use of questionnaires is a cost-efficient method essential in epidemiological studies, and it allows researchers to acquire a great deal of data from a large cohort of responders. Specifically, it allowed us to identify the burden of musculoskeletal disorders and associated factors within a military population whose occupational 
Table 4 Univariate regression analyses: adjusted OR for back and lower extremity pain limiting work ability, with rated work-related factors

\begin{tabular}{|c|c|c|c|c|c|c|c|c|c|c|}
\hline & \multicolumn{5}{|c|}{ Back } & \multicolumn{5}{|c|}{ Lower extremity } \\
\hline & $\bar{n}$ & Cases (\%) & $\mathrm{OR}^{\star}$ & $95 \% \mathrm{Cl}$ & p Value & $\bar{n}$ & Cases n (\%) & $\mathbf{O R}^{*}$ & $95 \% \mathrm{Cl}$ & p Value \\
\hline \multicolumn{11}{|c|}{ Military occupational function } \\
\hline Infantry (assault) & 95 & $18(19)$ & 1.00 & & & 96 & $30(31)$ & 1.00 & & \\
\hline Infantry (Hw) & 17 & $5(29)$ & 1.78 & 0.56 to 5.70 & 0.330 & 21 & $9(43)$ & 1.62 & 0.62 to 4.27 & 0.329 \\
\hline Ranger/EOD & 32 & $11(34)$ & 2.24 & 0.92 to 5.48 & 0.076 & 30 & $13(43)$ & 1.69 & 0.73 to 3.92 & 0.223 \\
\hline CBC-Crew & 25 & $8(32)$ & 2.02 & 0.75 to 5.42 & 0.163 & 28 & $12(43)$ & 1.68 & 0.71 to 3.98 & 0.243 \\
\hline $\begin{array}{l}\text { Command and } \\
\text { control }\end{array}$ & 18 & $8(44)$ & 3.41 & 1.18 to 9.90 & 0.024 & 21 & $7(33)$ & 1.06 & 0.38 to 2.92 & 0.910 \\
\hline Logistics & 14 & $3(21)$ & 1.16 & 0.29 to 4.63 & 0.943 & 14 & $7(50)$ & 2.07 & 0.66 to 6.56 & 0.215 \\
\hline \multicolumn{11}{|c|}{ Time in combat craft (h/week) } \\
\hline 0 & 110 & $26(24)$ & 1.00 & & & 118 & $41(35)$ & 1.00 & & \\
\hline $0.1-4.9$ & 53 & $16(30)$ & 1.40 & 0.67 to 2.99 & 0.367 & 55 & $23(42)$ & 1.41 & 0.73 to 2.74 & 0.310 \\
\hline$\geq 5$ & 24 & $8(33)$ & 1.61 & 0.62 to 4.19 & 0.331 & 25 & $12(48)$ & 1.70 & 0.71 to 4.07 & 0.236 \\
\hline \multicolumn{11}{|c|}{ Vibrating floor/seat (work day) } \\
\hline$\leq 1 / 10$ & 149 & $40(27)$ & 1.00 & & & 156 & $60(38)$ & 1.00 & & \\
\hline $1 / 4$ & 25 & $6(24)$ & 0.86 & 0.32 to 2.31 & 0.767 & 24 & $6(25)$ & 0.54 & 0.20 to 1.44 & 0.219 \\
\hline$\geq 1 / 2$ & 25 & $7(28)$ & 1.06 & 0.41 to 2.75 & 0.901 & 28 & $12(43)$ & 1.24 & 0.55 to 2.81 & 0.610 \\
\hline \multicolumn{11}{|c|}{ Computer work (work day) } \\
\hline$\leq 1 / 10$ & 143 & $24(17)$ & 1.00 & & & 145 & $52(36)$ & 1.00 & & \\
\hline $1 / 4$ & 28 & $15(54)$ & 5.72 & 2.41 to 13.55 & 0.000 & 33 & $15(45)$ & 1.48 & 0.69 to 3.19 & 0.312 \\
\hline$\geq 1 / 2$ & 30 & $14(47)$ & 4.43 & 1.89 to 10.39 & 0.001 & 32 & $11(34)$ & 0.95 & 0.42 to 2.16 & 0.904 \\
\hline \multicolumn{11}{|c|}{ Lifting >15 kg (work day/week) } \\
\hline$\leq 1$ & 85 & $26(31)$ & 1.00 & & & 82 & $31(38)$ & 1.00 & & \\
\hline $2-4$ & 74 & $19(26)$ & 0.78 & 0.39 to 1.57 & 0.493 & 84 & $35(42)$ & 1.18 & 0.63 to 2.19 & 0.610 \\
\hline$\geq 1$ & 41 & $8(20)$ & 0.55 & 0.22 to 1.35 & 0.193 & 42 & $12(29)$ & 0.67 & 0.30 to 1.50 & 0.329 \\
\hline
\end{tabular}

tasks are hard to systematically observe in their natural context. The questions regarding prevalence of musculoskeletal pain, that is, the basis of the primary outcomes, were adopted from international consensus definitions for population-based prevalence surveys, reporting not only prevalence of pain, but also pain affecting work ability, that is, activity-limiting pain. ${ }^{32}$

Our results showed that $78 \%$ of the SAF marines experienced musculoskeletal pain somewhere in the body within the previous 6 -month period. The occurrence of lumbar back and neck pain, at $36 \%$ and $20 \%$, respectively, was similar to previous reported prevalence for both deployed military personnel ${ }^{14}$ as well as global civilians' 12-month pain prevalence. ${ }^{5} 633$ Taking the mean age and primarily male gender of the population into consideration, a lower percentage of both low back pain (LBP) and neck pain was expected, as female gender $^{56}$ and older age ${ }^{63}$ have been associated with increased prevalence of musculoskeletal pain. Second to the lumbar back, the knee was found to be the most prevalent anatomical region of prior pain, which was in line with previous studies among marines and the general military population, both on and off deployment. $^{7} 834$ The reported prevalence of occupationalrelated knee or lower extremity pain in the civilian population is frequently limited to osteoarthritis, ${ }^{35}$ and consequently include study populations of older ages. Even so, the $35 \%$ prevalence of knee pain found in this relatively young population was higher than the 12-month prevalence of $22 \%$ reported for the general Dutch population $^{36}$ and the $21 \%$ reported among newly employed young British workers, ${ }^{37}$ but not as high as the $44 \%$ experienced by Swedish elite athletes. ${ }^{38}$ The reported occurrence of knee pain among marines was also comparable to the prevalence in other specific occupations such as miners and farmers. ${ }^{39}{ }^{40}$ Even if the present cohort differs substantially with regard to mean age and overall work tasks, these occupations are also versatile in nature, and are likely to involve repeated knee bending and possibly heavy lifting. Studies conducted on such occupations should also, we believe, quantify body exposures to long duration activities, such as long working hours and exposure to whole body vibrations, variables which are certainly present in marines.

Only one out of three marines who was experiencing pain in more than one region reported related limitations in work ability. This is somewhat contradictory to other studies where musculoskeletal comorbidity has shown increased reduction in function. ${ }^{41}{ }^{42}$ About half 
Table 5 Multiple regression analyses: initial and final adjusted* OR for back pain limiting work ability

\begin{tabular}{|c|c|c|c|c|c|c|}
\hline & \multicolumn{3}{|c|}{ Initial model } & \multicolumn{3}{|c|}{ Final model } \\
\hline & $\overline{\text { OR† }}$ & $95 \% \mathrm{Cl}$ & p Value & $\overline{\text { OR }^{\star}}$ & $95 \% \mathrm{Cl}$ & p Value \\
\hline \multicolumn{7}{|l|}{ Age (years) } \\
\hline$\leq 21$ & 1.00 & & & & & \\
\hline 22-26 & 0.50 & 0.15 to 1.60 & 0.241 & & & \\
\hline$\geq 27$ & 2.47 & 0.72 to 8.52 & 0.152 & & & \\
\hline $\mathrm{BMI}$ & 1.11 & 0.96 to 1.28 & 0.171 & & & \\
\hline \multicolumn{7}{|l|}{ Body height (m) } \\
\hline$\leq 1.80$ & 4.81 & 1.54 to 15.03 & 0.007 & 4.97 & 1.64 to 15.08 & 0.005 \\
\hline $1.81-1.85$ & 1.00 & & & & & \\
\hline$\geq 1.86$ & 4.35 & 1.33 to 14.21 & 0.015 & 4.40 & 1.38 to 14.05 & 0.012 \\
\hline \multicolumn{7}{|c|}{ Physical training (day/week) } \\
\hline$\leq 1$ & 4.88 & 1.49 to 15.93 & 0.009 & 5.29 & 1.66 to 16.84 & 0.005 \\
\hline $2-4$ & 1.00 & & & & & \\
\hline$\geq 5$ & 2.00 & 0.75 to 5.30 & 0.165 & & & \\
\hline \multicolumn{7}{|c|}{ Military occupational function } \\
\hline Assault infantry & 1.00 & & & & & \\
\hline Hw infantry & 0.93 & 0.22 to 4.01 & 0.922 & & & \\
\hline Ranger/EOD & 1.47 & 0.45 to 4.81 & 0.524 & & & \\
\hline CBC-Crew & 1.95 & 0.54 to 6.99 & 0.304 & & & \\
\hline Command and Control & 1.50 & 0.35 to 6.37 & 0.581 & & & \\
\hline Logistics & 1.03 & 0.19 to 5.56 & 0.974 & & & \\
\hline \multicolumn{7}{|l|}{ Computer work (work day) } \\
\hline$\leq 1 / 10$ & 1.00 & & & & & \\
\hline $1 / 4$ & 3.23 & 0.92 to 11.32 & 0.067 & 3.22 & 1.04 to 10.03 & 0.043 \\
\hline$\geq 1 / 2$ & 3.56 & 1.07 to 11.82 & 0.038 & 3.34 & 1.11 to 10.10 & 0.032 \\
\hline \multicolumn{7}{|c|}{ Lifting >15 kg (work day/week) } \\
\hline$\leq 1$ & 1.00 & & & & & \\
\hline $2-4$ & 1.14 & 0.48 to 2.74 & 0.761 & & & \\
\hline$\geq 5$ & 0.90 & 0.28 to 2.89 & 0.854 & & & \\
\hline
\end{tabular}

the marines in the present study with knee pain and two-fifths of those with LBP reported consequential limitations in their work ability. For back pain, this is similar to civilian populations where about half of the sufferers report disabilities in conjunction with experiencing

Table 6 Multiple regression analyses: initial adjusted ${ }^{*}$ OR for lower extremity pain limiting work ability

\begin{tabular}{|c|c|c|c|}
\hline & \multicolumn{3}{|c|}{ Initial model } \\
\hline & OR $^{*}$ & $95 \% \mathrm{Cl}$ & p Value \\
\hline \multicolumn{4}{|c|}{ Muscular strength training (h/week) } \\
\hline$<1.5$ & 0.53 & 0.26 to 1.08 & 0.079 \\
\hline $1.5-3.5$ & 1.00 & & \\
\hline$>3.5$ & 0.70 & 0.34 to 1.44 & 0.334 \\
\hline \multicolumn{4}{|c|}{ Mental component summary } \\
\hline$\leq 51.40$ & 0.69 & 0.34 to 1.42 & 0.311 \\
\hline $51.41-54.74$ & 0.57 & 0.28 to 1.17 & 0.126 \\
\hline$>54.75$ & 1.00 & & \\
\hline \multicolumn{4}{|c|}{$\begin{array}{l}\text { Adjusted OR with corresponding } 95 \% \mathrm{Cl} \text { and significance level } \\
\text { (p value) lower extremity (hip, knee and foot) pain limiting work } \\
\text { ability. } \\
{ }^{*} \text { Adjusted for comorbidity (non-musculoskeletal). }\end{array}$} \\
\hline
\end{tabular}

LBP. $^{33}$ Still, we expected a smaller influence on work ability since most marines who seek medical attention for their musculoskeletal pain problems elect to stay on full active duty. While we have found no comparable studies measuring limitations in work ability or function for marine units in garrison, studies on marine units in the predeployment phase reported an average loss of 6.1 days of work per person year due to musculoskeletal disorders $^{2}$ and 27 out of 1000 days for similar units when deployed. ${ }^{4}$

Physical training 1 day per week or less, that is, less than that recommended by the American College of Sports Medicine ${ }^{23}$ for the general population or the physical standards of the SAF, emerged strongly and independently associated with back pain limiting work ability. While the direction of temporality cannot be determined in this cross-sectional study, that is, whether physical training 1 day per week or less is the cause or the effect of back pain, the association identified a subgroup of marines where further medical attention, such as clinical evaluation and secondary preventive actions, is warranted. Physical activity is generally recommended for primary prevention of LBP as well as prevention of 
recurrence and duration of LBP in the general working population. ${ }^{43}$ If also taking the episodic nature of back pain into consideration, that is, irregular pain episodes rather than chronicity or a specific end point without recurrence of pain, ${ }^{44}$ correctly prescribed physical exercise for marines with few weekly training sessions could be a suitable secondary preventive action for limited work ability. In line with our hypothesis, the regression analyses also revealed a u-shaped relationship with body height and back pain limiting work ability, irrespective of body composition. While body height is not among the core variables recommended to be included in exposure measurements for cohort studies on back pain, ${ }^{45}$ taller than average body height has been reported to be associated with back pain in a few civilian and military studies among adults ${ }^{47}$ and adolescents. ${ }^{48}$ However, we have found no literature about associations between being shorter than average and back pain. From a biomechanical and ergonomic perspective, the present identified associations are likely to represent different underlying active mechanisms, which could be either individual (such as lifting from ergonomically unfavourable positions) or factors embedded in the marine occupation that were not identified or included in this study. Possibly, the equipment, such as body armour, back-packs and diving equipment, as well as transport (combat craft and armoured vehicles) and office equipment are designed for the 'average' marine, thus increasing the biomechanical demands for both shorter and taller marines. Also, computer work was associated with back pain limiting work ability. In civilian office workers, daily computer work has been found not to predict the onset of $\mathrm{LBP}^{49}$ possibly indicating that the present association could be multifactorial, that is, a result of combinations of exposures not under study. For example, this study did not further explore equipment worn nor whether computer work was conducted in the office or in the field. Increased time spent on computer work could possibly also represent a consequence rather than be a cause of back pain, that is, a work that is performed in order to avoid more strenuous or pain-aggravating tasks. Individual opportunities for such work modification are, however, limited for most SAF marines as work tasks are linked to military occupational specialty and grade. Nonetheless, technical innovation tends to increase SAF marines' use of computers in the field and in the future, marines will simultaneously hold civilian positions where exposure to computer work will probably increase. We, therefore, believe it is important to further investigate this finding for this occupational group.

The SAF marines reported mental health as well as mental component summary scores higher than the average Swedish population. ${ }^{21}$ The majority of marines $(>95 \%)$ reported mental health scores over 52, which has been suggested for use as a cut-off point for reduced mental well-being. ${ }^{21}$ Neither was there an association between the mental component summary scores and painrelated reduction in work ability. This was somewhat unexpected as musculoskeletal disorders have been associated with depression, post-traumatic stress disorders and poorer levels of well-being in non-deployed military personnel and military veterans. ${ }^{50}$ Therefore, even if the present results indicate overall good mental health and HRQL in SAF marines, the relationship between mental health and musculoskeletal pain in this population should be further investigated in future longitudinal studies.

In conclusion, this study shows that musculoskeletal pain and limitations in work ability due to pain are common in SAF marines. Regression analyses suggest that low frequency of physical training as well as being among the shorter or taller marines are the most important associated factors for back pain limiting work ability. As such, marines performing physical training 1 day per week or less are suitable candidates for further medical evaluation and secondary preventive actions, while the association with body height needs further investigation from a biomechanical and ergonomic perspective. Substantial time with computer work was also associated, but is possibly biased with other factors not under study. Interestingly, no factor included in the present study emerged as significant for lower extremity pain limiting work ability. Further, prospective studies are necessary to evaluate the associated factors and to clarify the direction of cause and effect.

\section{Author affiliations}

${ }^{1}$ Department of Neurobiology, Care Sciences and Society, Division of Physiotherapy, Karolinska Institutet, Huddinge, Stockholm, Sweden

${ }^{2}$ Swedish Armed Forces, Regional Medical Service Mälardalen, Berga, Sweden ${ }^{3}$ Swedish Armed Forces, HR Centre, Stockholm, Sweden

${ }^{4}$ Department of Occupational and Public Health Sciences, Centre for Musculoskeletal Research, University of Gävle, Gävle, Sweden

${ }^{5}$ Department of Medical Engineering, School of Technology and Health, KTH Royal Institute of Technology, Huddinge, Sweden

${ }^{6}$ Centre for Clinical Research Dalarna, Falun, Sweden

${ }^{7}$ Karolinska University Hospital, Stockholm, Sweden

Acknowledgements Funding from the Swedish Armed Forces PhD Programme and financial support from the Swedish Society for Military Medical Officers is gratefully acknowledged. The authors also thank the 1st Marine Regiment, Swedish Armed Forces, for funding and overall support, and the authors especially extend our thanks to the marines who participated. The authors would also like to thank Kjell Norman, RPT, 2nd Amphibious Battalion, Swedish Armed Forces, for valuable support and comments on our work.

Contributors AM was the main writer of the paper and participated in the conception and design of the study, acquisition, analysis and interpretation of the data. $\mathrm{HL}$ and MD participated in the planning and interpretation of the data as well as in writing and revising the paper. L-ÅB was involved in the design and planning of the study, and revising of the paper. BOÄ was the senior project researcher, participating in the conception and design of the study, analysing and interpreting the data, and in the writing as well as revising of the paper. All the authors read and approved the final manuscript.

Funding This study was funded from 1st Marine Regiment, Swedish Armed Forces, the Swedish Armed Forces PhD Programme and financial support was also received from the Swedish Society for Military Medical Officers. The funding organisations had no authority over or input into any part of this study.

Competing interests None declared.

Ethics approval The Regional Medical Research Ethics Committee, Stockholm, Sweden. 
Provenance and peer review Not commissioned; externally peer reviewed.

Data sharing statement No additional data are available.

Open Access This is an Open Access article distributed in accordance with the Creative Commons Attribution Non Commercial (CC BY-NC 4.0) license, which permits others to distribute, remix, adapt, build upon this work noncommercially, and license their derivative works on different terms, provided the original work is properly cited and the use is non-commercial. See: http:// creativecommons.org/licenses/by-nc/4.0/

\section{REFERENCES}

1. Hayton J. Reducing medical downgrading in a high readiness Royal Marine unit. JR Army Med Corps 2004:150:164-7.

2. Hollingsworth $D$. The prevalence and impact of musculoskeletal injuries during a pre-deployment workup cycle: survey of a Marine Corps special operations company. J Spec Oper Med 2009;9:11-15.

3. Skeehan CD, Tribble DR, Sanders JW, et al. Nonbattle injury among deployed troops: an epidemiologic study. Mil Med 2009; 174:1256-62.

4. Roy TC, Knapik JJ, Ritland BM, et al. Risk factors for musculoskeletal injuries for soldiers deployed to Afghanistan. Aviat Space Environ Med 2012;83:1060-6.

5. Hoy $\mathrm{D}$, Brooks $\mathrm{P}$, Blyth $\mathrm{F}$, et al. The epidemiology of low back pain. Best Pract Res Clin Rheumatol 2010;24:769-81.

6. Hoy D, Protani M, De R, et al. The epidemiology of neck pain. Best Pract Res Clin Rheumatol 2010;24:783-92.

7. Hauret KG, Jones BH, Bullock SH, et al. Musculoskeletal injuries description of an under-recognized injury problem among military personnel. Am J Prev Med 2010;38:S61-70.

8. Kaufman KR, Brodine S, Shaffer R. Military training-related injuries: surveillance, research, and prevention. Am J Prev Med 2000;18:54-63.

9. Knapik JJ, Graham B, Cobbs J, et al. A prospective investigation of injury incidence and injury risk factors among army recruits in military police training. BMC Musculoskelet Disord 2013;14:32

10. Mattila VM, Sahi T, Jormanainen V, et al. Low back pain and its risk indicators: a survey of 7,040 Finnish male conscripts. Eur Spine $J$ 2008;17:64-9.

11. Knapik JJ, Graham B, Cobbs J, et al. A prospective investigation of injury incidence and risk factors among army recruits in combat engineer training. J Occup Med Toxicol 2013;8:5.

12. Knox J, Orchowski J, Scher DL, et al. The incidence of low back pain in active duty United States military service members. Spine 2011;36:1492-500.

13. MacGregor AJ, Dougherty AL, Mayo JA, et al. Occupational correlates of low back pain among US Marines following combat deployment. Mil Med 2012;177:845-9.

14. Konitzer LN, Fargo MV, Brininger TL, et al. Association between back, neck, and upper extremity musculoskeletal pain and the individual body armor. J Hand Ther 2008;21:143-8; quiz 149.

15. Owens BD, Wolf JM, Seelig AD, et al. Risk factors for lower extremity tendinopathies in military personnel. Orthop J Sports Med 2013;1:2325967113492707.

16. Knapik JJ, Canham-Chervak M, Hoedebecke E, et al. The fitness training unit in US Army basic combat training: physical fitness, training outcomes, and injuries. Mil Med 2001;166:356-61.

17. Almeida SA, Williams K, Shaffer RA, et al. Epidemiological patterns of musculoskeletal injuries and physical training. Med Sci Sports Exerc 1999;31:1176-82.

18. Kuorinka I, Jonsson B, Kilbom A, et al. Standardised Nordic questionnaires for the analysis of musculoskeletal symptoms. Appl Ergon 1987; 18:233-7.

19. Wiktorin $\mathrm{C}$, Vingård $\mathrm{E}$, Mortimer $\mathrm{M}$, et al. Interview versus questionnaire for assessing physical loads in the population-based MUSIC-Norrtälje study. Am J Ind Med 1999;35:441-55.

20. Larsson H, Broman L, Harms-Ringdahl K. Individual risk factors associated with premature discharge from military service. Mil Med 2009;174:9-20.

21. Sullivan M, Karlsson J, Taft C, et al. SF-36 Health Survey. Swedish manual and interpretation guide. Gothenburg: Sahlgrenska University Hospital, 2002

22. Stock SR, Fernandes R, Delisle A, et al. Reproducibility and validity of workers' self-reports of physical work demands. Scand J Work Environ Health 2005;31:409-37.

23. Garber CE, Blissmer B, Deschenes MR, et al. American College of Sports Medicine position stand. Quantity and quality of exercise for developing and maintaining cardiorespiratory, musculoskeletal, and neuromotor fitness in apparently healthy adults: guidance for prescribing exercise. Med Sci Sports Exerc 2011;43:1334-59.
24. Leboeuf-Yde C. Body weight and low back pain. A systematic literature review of 56 journal articles reporting on 65 epidemiologic studies. Spine 2000;25:226-37.

25. Vingård $\mathrm{E}$, Alfredsson L, Hagberg $\mathrm{M}$, et al. To what extent do current and past physical and psychosocial occupational factors explain care-seeking for low back pain in a working population? Results from the musculoskeletal intervention Center-Norrtälje study. Spine 2000;25:493-500

26. Mazic S, Djelic M, Suzic J, et al. Overweight in trained subjects-are we looking at wrong numbers?(body mass index compared with body fat percentage in estimating overweight in athletes). Gen Physiol Biophys 2009;28:200-4.

27. Carragee EJ, Cohen SP. Lifetime asymptomatic for back pain: the validity of self-report measures in soldiers. Spine 2009;34:978-83.

28. Monnier A, Heuer J, Norman K, et al. Inter- and intra-observer reliability of clinical movement-control tests for marines. BMC Musculoskelet Disord 2012;13:263.

29. Hosmer DW Jr, Lemeshow S, Sturdivant RX. Applied logistic regression. 3rd edn. John Wiley \& Sons, Inc., 2013.

30. Munnoch K, Bridger RS. Investigation of the operational effectiveness of Hunter Company, Commando Training Centre, Royal Marines. Mil Med 2008;173:129-33.

31. Spielholz P, Silverstein B, Morgan M, et al. Comparison of self-report, video observation and direct measurement methods for upper extremity musculoskeletal disorder physical risk factors. Ergonomics 2001:44:588-613.

32. Dionne CE, Dunn KM, Croft PR, et al. A consensus approach toward the standardization of back pain definitions for use in prevalence studies. Spine 2008;33:95-103.

33. Hoy D, Bain C, Williams $G$, et al. A systematic review of the global prevalence of low back pain. Arthritis Rheum 2012;64:2028-37.

34. Cohen SP, Brown C, Kurihara C, et al. Diagnoses and factors associated with medical evacuation and return to duty for service members participating in Operation Iraqi Freedom or Operation Enduring Freedom: a prospective cohort study. Lancet 2010;375:301-9.

35. D'Souza JC, Franzblau A, Werner RA. Review of epidemiologic studies on occupational factors and lower extremity musculoskeletal and vascular disorders and symptoms. J Occup Rehabil 2005;15:129-65.

36. Picavet $\mathrm{H}$, Schouten J. Musculoskeletal pain in the Netherlands: prevalences, consequences and risk groups, the DMC(3)-study. Pain 2003:102:167-78.

37. Jones GT, Harkness EF, Nahit ES, et al. Predicting the onset of knee pain: results from a 2-year prospective study of new workers. Ann Rheum Dis 2007:66:400-6.

38. Jonasson P, Halldin K, Karlsson J, et al. Prevalence of joint-related pain in the extremities and spine in five groups of top athletes. Knee Surg Sports Traumatol Arthrosc 2011;19:1540-6.

39. O'Reilly S, Muir K, Doherty M. Occupation and knee pain: a community study. Osteoarthritis Cartilage 2000;8:78-81.

40. Gomez M, Hwang S, Stark A, et al. An analysis of self-reported joint pain among New York farmers. J Agric Saf Health 2003;9:143.

41. Bruusgaard D, Tschudi-Madsen $\mathrm{H}$, Ihlebaek $\mathrm{C}$, et al. Symptom load and functional status: results from the Ullensaker population study. BMC Public Health 2012;12:1085.

42. Miranda $\mathrm{H}$, Kaila-Kangas L, Heliövaara $\mathrm{M}$, et al. Musculoskeletal pain at multiple sites and its effects on work ability in a general working population. Occup Environ Med 2010;67:449-55.

43. Burton AK, Balagué $F$, Cardon $\mathrm{G}$, et al. Chapter 2 European guidelines for prevention in low back pain. Eur Spine J 2006;15:S136-68.

44. Axén I, Leboeuf-Yde C. Trajectories of low back pain. Best Pract Res Clin Rheumatol 2013;27:601-12.

45. Pincus T, Santos R, Breen A, et al. A review and proposal for a core set of factors for prospective cohorts in low back pain: a consensus statement. Arthritis Rheum 2008;59:14-24.

46. Kopec JA, Sayre EC, Esdaile JM. Predictors of back pain in a general population cohort. Spine 2004:29:70-7.

47. Orsello CA, Phillips AS, Rice GM. Height and in-flight low back pain association among military helicopter pilots. Aviat Space Environ Med 2013;84:32-7.

48. Hershkovich O, Friedlander A, Gordon B, et al. Associations of body mass index and body height with low back pain in 829,791 adolescents. Am J Epidemiol 2013;178:603-9.

49. Janwantanakul P, Sitthipornvorakul E, Paksaichol A. Risk factors for the onset of nonspecific low back pain in office workers: a systematic review of prospective cohort studies. J Manipulative Physiol Ther 2012;35:568-77.

50. Kelsall HL, McKenzie DP, Forbes AB, et al. Pain-related musculoskeletal disorders, psychological comorbidity and the relationship with physical and mental wellbeing in Gulf War veterans. Pain 2014;155:685-92. 